\title{
Looking Back from the Future to the Present: Biopreservation Will Get Us There!
}

\author{
Andreas Sputtek $^{\mathrm{a}}$ Arthur W. Rowe \\ ${ }^{a}$ Institut für Transfusionsmedizin, Universitätsklinikum Hamburg-Eppendorf, Hamburg, Germany \\ ${ }^{\mathrm{b}}$ New York University School of Medicine, New York, NY, USA
}

Biopreservation is a rapidly emerging field of specimen procurement, processing, preservation and banking. Such biospecimens can be macromolecules, fungi, viruses, bacteria, cells, tissues and organs. The discipline requires a close collaboration between clinicians, engineers and scientists coming from academia, small private enterprises or huge industrial companies. What they all have in common is the ultimate goal to preserve life, hence the word 'biopreservation' (from 'bios' $($ Greek $)=$ life, and 'preservare' $($ Latin $)=$ to keep). But what is the definition of 'life'? Provided a rather limited biological definition is acceptable here, life can defined as 'a process requiring energy and mass exchange, growth, reproduction and reactions to changes in the environment, completed by coordination via communication. Some of these criteria can be found in technical, physical and chemical systems, while other criteria can be found in living organisms. However, the minimum quality of all living systems is autopoiesis: the capability of self-preservation and reproduction' [1].

It is hard to define what all of the various approaches trying to achieve 'biopreservation' have in common, but one central theme is the ability to remove or immobilize water. In other words: Although most biospecimens (including animals and human beings) cannot 'live' without water on the one hand, the presence of diffusible water leads to eventual aging followed by death on the other hand. Over the course of several thousand years mankind has developed different approaches to reduce water activity, the first (and simplest one) is drying. Nevertheless, more 'ambitious' proteins require another procedure besides drying: It is freezing. Extremely 'sensitive' proteins are best preserved using a technique combining both approaches; this is known as freezedrying or lyophilization. Here water is first immobilized at low temperatures ('frozen') and then removed by vacuum sublimation also at low temperatures until the water content becomes very low, i.e. $10 \%$ or less. Once water has been sublimed or evaporated, the compound is stable at room temperature - under refrigeration, if more than a few percent of 'residual moisture' remains. Life requires the capability of self-preservation and reproduction, but are proteins able to reproduce? The answer (until some 30 years ago) would have been 'no', but we have learned better in the meantime. Prions (= proteinacious infectious particles) are in fact macromolecules that exist in animals and humans as their hosts and, depending upon the scenario, they may have a normal or a pathological conformation. The relationship to viruses, bacteria and fungi is close, although the difference is obvious: They have no DNA or RNA, but nevertheless they are able to replicate. So when a pathologist freezes a part of a brain for further investigations on such prions, he actually 'biopreserves' a protein (but unfortunately destroys the brain). Whereas the latter approach is a highly 'intended' branch of biopreservation (accompanied by biodestruction), nature itself has applied biopreservation since the existence of life. One only has to think of algae and cyanobacteria which 'survive' in the Arctic $\left(-10\right.$ to $\left.-20{ }^{\circ} \mathrm{C}\right)$ and in the Antarctic (down to $-65^{\circ} \mathrm{C}$ ) environments under permafrost conditions. The diversity of microorganisms living in permafrost soils is huge, and some algae and bacteria are already over 3 million years 'old' [2].

Today's 'facilitated reproduction' is hardly thinkable without biopreservation, a consequence of Polge's rather accidental but nevertheless revolutionary discovery that glycerol was able to protect spermatozoa from damage during freezing and thawing [3]. The truth behind this discovery is that a technician had confused some reagent bottle labels which had become unglued in the damp atmosphere of the cold room and he erroneously thought he had placed them back on the original bottles. As a consequence thereof, a glycerol-containing solution was used by mistake instead of the intended sugar solutions that did not work. Today, the

\section{KARGER}

Fax +497614520714

Information@Karger.de

www.karger.com (c) 2011 S. Karger GmbH, Freiburg

Accessible online at:

www.karger.com/tmh 
cryopreservation of human male and female reproductive cells has become a routine laboratory technique, ranging from immature gametes in ovarian or testicular tissues through mature oocytes and spermatozoa to various stages of pre-implantation embryos [4]. Biopreservation in the form of cryopreservation has become an effective means in species conservation.

Polge's discovery led to a variety of cell-specific cryopreservation protocols for numerous cell types and tissues. These cryopreservation methods differ with regard to i) cell concentrations/tissue volume fraction, ii) protective solutions containing 'antifreezes' (which are more professionally called 'cryoprotectants') and their concentrations, iii) temperature-time histories (TTH) during cooling and re-warming (frequently condensed into the terms 'cooling and warming rates') and iv) storage temperature. Additionally, some of the cryoprotectants are not well tolerated in the concentrations required (e.g. dimethyl sulphoxide - properly abbreviated ' $\mathrm{Me}_{2} \mathrm{SO}$ ', not 'DMSO', as frequently found in the literature (including the authors' own publications)). The cryoprotectant glycerol flows in and out of cells readily, but frozen/thawed red cells hypertonically loaded with glycerol will experience an osmotically induced lysis if transfused into an isotonic recipient if the glycerol is not removed prior to transfusion. In this and similar cases, a washing procedure is required after thawing to remove the glycerol prior to clinical application. 'Biopreserved' autologous and homologous peripheral blood stem cells as well as allogeneic and autologous umbilical cord blood stem cells are being routinely cryopreserved. Peripheral blood stem cells and allogeneic (in contrast to autologous) umbilical cord blood stem cells, in combination with high-dose chemotherapy and/or irradiation, have become a 'standard' blood component for the treatment of several malignant diseases.

Where would we be today in biotechnology without cellline banks? Some 50 years ago human diploid fibroblast cell lines were developed for the production of vaccines, and nowadays, who thinks about the hybridoma cell lines which are so helpful for the production of monoclonal antibodies that we use for both therapeutic and diagnostic purposes? It has to be mentioned here that 60 years ago an early remarkable case of unintentional 'viral biopreservation' took place as well when batches of polio vaccine were contaminated with Simian virus 40 from the primary monkey kidney cells in which the virus was manufactured. Virus transmission has been reported to happen during cryogenic storage in or even above liquid nitrogen (to the best of our knowledge the latter has been reported only once). However - and this is the good news - transmission can only happen if i) the freezing bag in question is leaky and ii) the liquid nitrogen tank has already been contaminated. In most cases such damage has happened prior to thawing (we would like to say mostly because of improper sealing and improper handling of freezing specimen bags). This brings up another problem for all kinds of cell banks: Obviously not only is the 'desired species' able to withstand a suitable 'biopreservation' protocol, but also potential 'cross-contamination' is a big concern in the cell banking 'business' [5].

More than a decade ago one of the authors published an editorial in the precursor of this journal [6] and was prescient enough to note that blood banking can be regarded as the first step to tissue and organ banking. Two facts are evident: The demand for tissues and organs increases steadily, whereas the market for blood cell products is almost at a standstill in highly developed countries. Unfortunately there has been no breakthrough with regard to artificial oxygen carriers, thus requiring natural blood components to be used. Patients benefit from donated bone, cartilage, and tendons which are used to reconstruct defects. Corneas, skin grafts and heart valves are also being used increasingly. Blood, cell and tissue banks have become important adjuncts to medical treatment. People operating a blood bank are not only experts in biopreservation but also in organizational requirements (e.g. record keeping and working in accordance with standard operating procedures), acquisition (e.g. ethical and legal rules, anonymity, donor screening and selection), processing (e.g. identification, inspection, storage, expiration, irradiation, sterilization, freeze-drying, and quality management), labeling, distribution and transportation. Fortunately, the above mentioned prerequisites are already implemented in a modern blood bank.

If the gentle reader (probably a person in the field of transfusion medicine and immunohematology) is still willing to read what six of our distinguished colleagues wrote after being asked to comment on different aspects of biopreservation, she/he will be surprised to read in the multicontinental paper by Edgardo Guibert et al. [7] why and how hypothermia has become central to the process of organ preservation and what the current 'biopreservation' status is for a range of commonly transplanted solid organs (e.g. kidney, liver, heart, lung, pancreas, small bowel).

At present everybody talks about iPS (= induced pluripotent stem cells) as a potential more ethical alternative to embryonic stem cells, but who knows how their pluripotency is maintained throughout storage, e.g. by 'vitrification' as described by Charles Hunt [8] from the UK Stem Cell Bank in Potter's Bar?

The above mentioned reader will be surprised to learn of the parallels between the developments in cornea banking compared to blood banking as described by John Armitage [9] of Bristol Eye Bank, UK. All of this started with the first successful full-thickness corneal transplant in 1905 in England - only 4 years after Karl Landsteiner discovered the ABO blood groups.

Jelena Holovati and Jason Acker [10] from Edmonton, Canada, (it is extremely cold there in winters!) introduce us to the use of liposomes for the biopreservation of red cells. Those readers who thought so far that liposomes only played
86

Transfus Med Hemother 2011;38:85-87
Sputtek/Rowe 
a role in the cosmetic industry are cordially invited to study this paper.

Christoph Stoll and Willem Wolkers [11] (a GermanDutch cooperation) report on the effects of cryopreservation and lyophilization on the membranes of red cells and platelets - how far away are we from freeze-dried blood cells?

Those of us who are in contact with public health authorities in our respective countries are fully aware that these institutions like to focus on aspects of specimen containers and shipping (we dare to say sometimes neglecting the importance of the quality of the biological content). An interesting closed vial system for the shipment of e.g. mesenchymal stem cells is presented by Erik Woods and Sreedhar Thirumala [12] of Indianapolis, IN, USA. This is just another project Indianapolis may become proud of instead of racing cars!

\section{References}

1 Translated from: http://de.wikipedia.org/wiki/Leben

2 Vishnivetskaya T, Kathariou S, McGrath J, Tiedje JM: Low temperature recovery strategies for the isolation of bacteria from ancient permafrost sediments, Extremophiles 2000;4:165-173.

3 Polge C, Smith AU, Parkes AS: Revival of spermatozoa after vitrification and dehydratation at low temperatures, Nature 1949;164:666.

4 Fuller BJ, Paynter SJ, Watson P: Cryopreservation of human gametes and embryos; in Fuller BJ, Lane N, Bensson EE (eds): Life in the Frozen State. Boca Raton, CRC Press, 2004, pp 505-539.

5 Drexler HG, Dirks WG, MacLeod RA: False human hematopoietic cell lines: cross contaminations and misinterpretations. Leukaemia 1999;13:1601-1607.

6 Sputtek A: Low temperature biology meets transfusion medicine. Infusionsther Transfusionsmed 1997;24:364-366.

$>7$ Guibert EE, Petrenko AY, Balaban CL, Somov AY, Rodriguez JV, Fuller BJ: Organ preservation: current concepts and new strategies for the next decade. Transfus Med Hemother 2011;38(2):125-142.

8 Hunt CJ: Cryopreservation of human stem cells for clinical application: a review. Transfus Med Hemother 2011;38(2):107-123.

9 Armitage WJ: Preservation of human cornea. Transfus Med Hemother 2011; 38(2):143-147.

10 Holovati JL, Acker JP: Emerging role for use of liposomes in the biopreservation of red blood cells. Transfus Med Hemother 2011;38(2):99-106.

11 Stoll C, Wolkers WF:Membrane stability during biopreservation of blood cells. Transfus Med Hemother 2011;38(2):89-97.

12 Woods EJ, Thirumala S: Packaging considerations for biopreservation. Transfus Med Hemother 2011;38(2):149-156. 